\title{
Turbulence Anisotropy in a Sinuous Channel with Downward Seepage
}

\author{
Jyotismita TAYE $^{\bowtie}$ and Bimlesh KUMAR \\ Indian Institute of Technology, Guwahati, Assam, India \\ $\triangle$ taye176104022@iitg.ac.in
}

\begin{abstract}
The study estimates the turbulence anisotropy for flow in a sinuous channel under the influence of downward seepage. Anisotropy provides the deviation from the isotropic turbulence. Given the complex flow processes in a sinuous channel, it is vital to investigate the turbulent flow characteristics.
\end{abstract}

Keywords: turbulence, anisotropy, sinuous channel, seepage.

\section{INTRODUCTION}

The geometry of the channel may have a significant effect on the flow characteristics around the sinuous bend. Lumley and Newman (1977) defined the Reynolds stress anisotropy tensor to evaluate the turbulence structure to different bed condition. The Reynolds stress anisotropy tensor $\left(b_{i k}\right)$ is given as:

$$
b_{i j}=\frac{\overline{u_{\imath}{ }_{\imath}{ }_{\jmath}}}{2 k}-\frac{\delta_{i j}}{3}
$$

where $k$ is the average turbulent kinetic energy (TKE) and $\delta_{i j}$ is the Kronecker delta function, where $i, j=1,2,3$ are the spatial components. The anisotropic invariant map (AIM) is constructed to examine the anisotropy of Reynolds stress. AIM is represented using the two principal independent invariants (II and III). The AIM by can also be presented by plotting $\xi$ against $\eta$ because it produces less distortion in forming a triangle. The detailed methodology can be found in Raushan et al. (2020). With seepage, the flow parameters are modified near the channel bed. With downward seepage, the magnitude of Reynolds shear stress increased (Taye et al. 2020), and with upward seepage, the Reynolds shear stress decreased (Herrera-Granados and Kostecki 2017). 
The three-dimensional instantaneous velocities were recorded using a Nortek ${ }^{\circledR}$ Vectrino + Acoustic Doppler Velocimeter (4-beam probe down-looking). The velocimeter uses the Doppler shift principle for velocity measurement and delivers the velocities in three orthogonal directions (streamwise, transverse, and vertical). In the present study, the velocities were collected for 2 minutes with sampling frequency $100 \mathrm{~Hz}$. The SNR (signal-to-noise) was greater than 15 decibels and the correlation greater than $60 \%$ during data collection. For good result, the SNR should be greater than 15 decibels (Nortek 1997) and the correlation should be at least 60\% (McLelland and Nicholas 2000). The raw data was filtered by the acceleration threshold method, as it may sometimes be contaminated with spikes.

\section{RESULTS AND DISCUSSIONS}

The anisotropy at bend upstream and bend center tends to move towards the one-component isotropy for no seepage and seepage flows. At bend downstream, the anisotropy is reduced to two-component isotropy, as maximum points lie towards the left line, signifying the turbulence fluctuations to lead along two directions. At bend upstream and center, maximum points lie above the right line, which signify the fluctuations to dominate along one direction.

With seepage flows at bend upstream, the points reach one-component isotropy faster than at bend center, and further at bend downstream, the points are clustered near the two-component isotropy (Fig. 1).
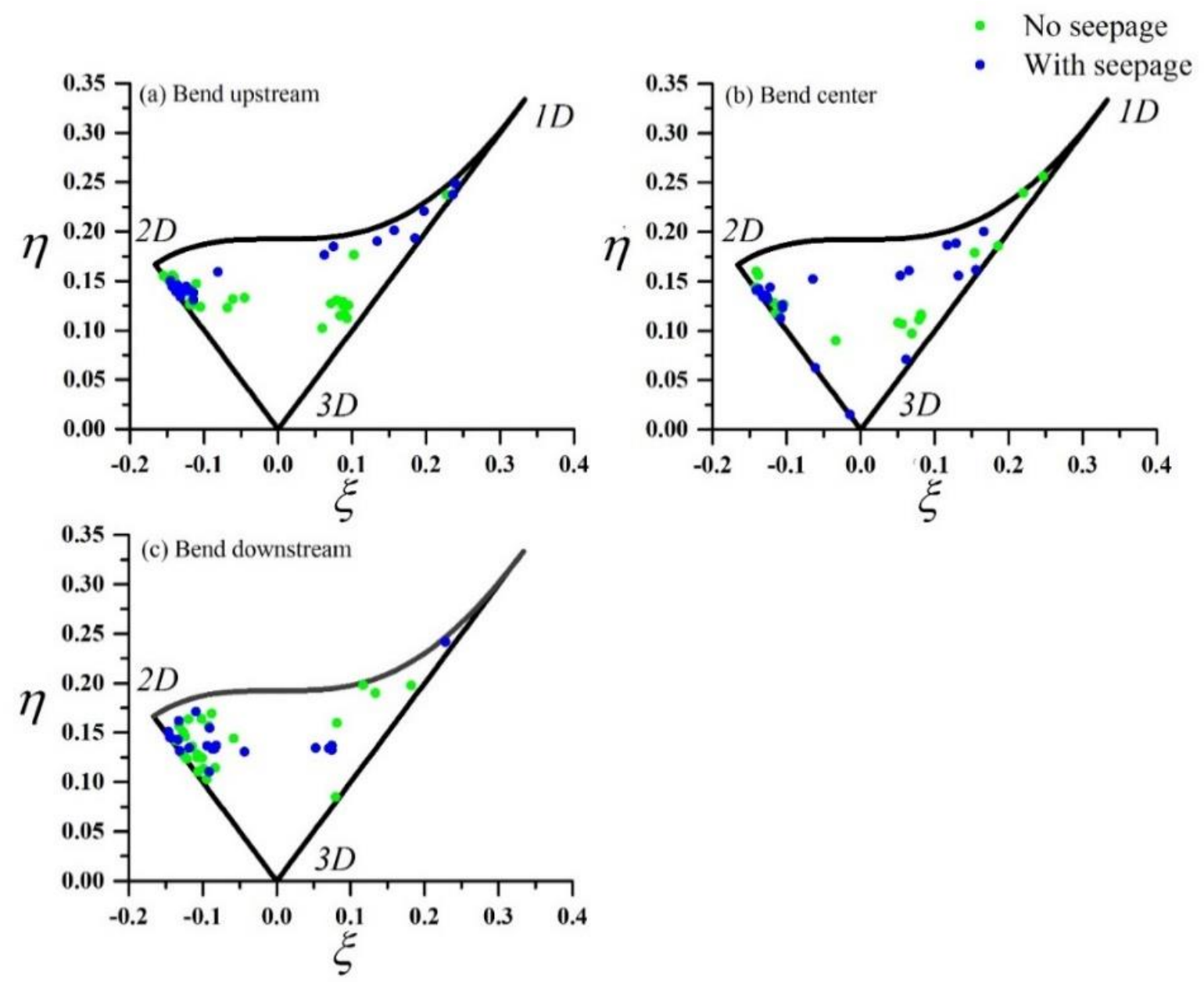

Fig. 1. Representation of Lumley triangle for no seepage and seepage flows at: (a) Bend upstream, (b) Bend center, and (c) Bend downstream. 


\section{References}

Herrera-Granados, O. and S.W. Kostecki (2017), Experimental study of the influence of small upward seepage on open-channel flow turbulence, J. Hydraul. Eng. 143, 8, 06017009, DOI: 10.1061/ (ASCE)HY.1943-7900.0001312.

Lumley, J.L., and G.R. Newman (1977), The return to isotropy of homogeneous turbulence, J. Fluid Mechanics 82, 1, 161-178, DOI: 10.1017/S0022112077000585.

McLelland, S.J., and A.P. Nicholas (2000), A new method for evaluating errors in high-frequency ADV measurements, Hydrol. Processes 14, 2, 351-366, DOI: 10.1002/(SICI)1099-1085(20000215) 14:2<351::AID-HYP963>3.0.CO;2-K.

Nortek (1997), ADV Operation manual, Nortek AS Inc.

Raushan, P.K., S.K. Singh, and K. Debnath (2020), Turbulence anisotropy with higher-order moments in flow through passive grid under rigid boundary influence, Proc. Inst. Mech. Eng., Part C: J. Mech. Eng. Sci., DOI: 10.1177/0954406220969736.

Taye, J., A.D. Lade, A. Mihailović, D.T. Mihailović, and B. Kumar (2020), Information measures through velocity time series in a seepage affected alluvial sinuous channel, Stoch. Environ. Res. Risk Assess. 34, 11, 1925-1938, DOI: 10.1007/s00477-020-01849-2.

Received 22 March 2021

Accepted 12 April 2021 